\title{
Lessons Learned from Long-Term Assessment of Rotavirus Vaccination in a High-Income Country: The Case of the Rotavirus Vaccine Belgium Impact Study (RotaBIS)
}

Baudouin Standaert · Danielle Strens · Priya Pereira • Bernd Benninghoff •

Marc Raes

Received: July 1, 2020 / Accepted: September 14, 2020 / Published online: October 6, 2020

(C) GlaxoSmithKline Biologicals S.A. 2020

\section{ABSTRACT}

Introduction: The rotavirus (RV) vaccine Belgium Impact Study (RotaBIS) evaluated the vaccine effect on RV-related hospital care in children up to 5 years old over a period of 13 years. Different forces were identified that influence the reduction in hospital care. Our analysis aims to report on the current RotaBIS dataset and explore through model simulation whether, how, and when the results could have been improved.

Methods: As performed in previous assessments, this analysis evaluated RV-related events per year, per age group, RV nosocomial infections, hospitalization duration, and herd effect.

Digital Features To view digital features for this article go to https://doi.org/10.6084/m9.figshare.12867050.

Electronic supplementary material The online version of this article (https://doi.org/10.1007/s40121020-00345-y) contains supplementary material, which is available to authorized users.

B. Standaert $(\square)$

HEBO, BV, Antwerp, Belgium

e-mail: baudouin.standaert@skynet.be

D. Strens

Realidad Bvba, Grimbergen, Belgium

P. Pereira - B. Benninghoff

GSK, Medical Affairs, Wavre, Belgium

M. Raes

Pediatrics, Jessa Ziekenhuis, Hasselt, Belgium
It subsequently identified results that were surprising or unexpected. To know whether those data could have been improved through specific interventions, we developed a model with the forces acting on the disease transmission and the vaccine effect on RV-related hospital care. Scenario analysis of the forces should explain the current findings and identify ways to optimize the results.

Results: The RotaBIS data show that annual RV-related hospital cases $(n=1345$ pre-vaccination) dropped by $70 \%$ (95\% confidence interval [CI] $66-74 \%)$ by year $5(n=395)$ after vaccine introduction, and by $84 \%$ (95\% CI $79-89 \%)$ by year $10(n=217)$. The herd effect during the first year was limited to $14 \%$ extra gain. During the last 5 years, small disease increases were seen biennially. The simulation model indicates that higher vaccine coverage of the major transmitters during the peak season of the first year of vaccination could have reduced RV-related hospital care by nearly $90 \%$ at 5 and 10 years after vaccine introduction owing to a higher herd effect. The smaller peaks observed in recent years would have been dramatically reduced.

Conclusion: The current RotaBIS data show a maintained reduction, around $76 \%$, in RV hospitalization cases. Simulations show that these results could have been improved to an important extent with a more optimal initiation of the vaccination program. 
Trial registration: ClinicalTrials.gov identifier, NCT01563146 and NCT01563159.

Keywords: Acute gastroenteritis; Children; Hospitalizations; Nosocomial; Rotavirus; Vaccination

\section{Key Summary Points}

\section{Why carry out this study?}

Rotavirus vaccination was introduced in Belgium in 2006.

Since then data have been collected annually in 10 hospitals in Belgium to measure the impact of the vaccination, assessing temporal changes in the proportion of positive rotavirus test results as compared with the prevaccination situation.

The present study looked at surprising results in the dataset and whether we could find an explanation for those through a modeling exercise by which we could improve the vaccine impact if we had to start elsewhere with this vaccination.

\section{What was learned from the study?}

The surprising results in the RotaBIS database were the weak response of the vaccine effect (direct and indirect) in the first year, the impact curve flattening after 3 years, and the small peaks appearing at years 9 and 11 post vaccine introduction.

The model showed that the selection of the starting date of the vaccination program and the level of vaccine coverage of the big transmitters of the virus during the next normal peak season determine the results of the exceptions.
Improvement of the vaccine effect in Belgium could have been achieved if the vaccination program had started

8-10 months before the peak season of the infection (in July in Belgium) and with a high coverage at the start. Under such conditions, a $90 \%$ drop in the proportion of positive rotavirus test results could have been reached after 5 years instead of the observed $70 \%$, along with a better longterm vaccine effect.

These results provide valuable insights for those countries wishing to initiate rotavirus vaccination.

\section{DIGITAL FEATURES}

This article is published with digital features to facilitate understanding of the article. To view digital features for this article go to https://doi. org/10.6084/m9.figshare.12867050.

\section{INTRODUCTION}

The human-bovine reassortant RotaTeq (Merck) and the single human rotavirus (RV) strain Rotarix (GSK) vaccines were introduced in 2006 and 2008, respectively, in the USA [1]. Those vaccines were also introduced in 2006 in Austria [2] and Belgium [3]. Other countries followed year after year across the world [4-10]. Still a number of high-income countries in Europe, such as France, Spain, the Netherlands, Denmark, Italy, and Switzerland, have not yet implemented systematic RV vaccine reimbursement.

The $R V$ vaccination that was launched in the aforementioned countries showed that vaccine coverage of the targeted group (children up to 5 years old) must be built up gradually over the 
years. Infants normally receive two or three doses of the vaccine between 2 and 6 months of age. During that uptake period, many different forces interact and affect the vaccine impact [11-14]. Together, these effects lead to new equilibria of infection spread in the child population over time $[15,16]$. This evolution needs to be analyzed in depth to better understand the vaccine impact and whether the results could be improved with more appropriate vaccination strategies.

With that purpose in mind, an initiative was started in 2007 in Belgium to collect retrospective data for each past year in the same sample group of hospitals across the country [17]. The study collected RV test results in hospital care (ambulatory and hospitalization) in children with diarrhea aged up to 5 years old, comparing the situation pre and post vaccine introduction. The study has been called RotaBIS (Rotavirus Belgian Impact Study). We have regularly followed up and reported the results during the past 10 years [16-19]

This paper aims to describe the observational data currently over 15 years ( 2 pre-vaccination years and 13 post-vaccination years). It follows the same analysis as in our previous report done after 7 years of evaluation [16-19], but we added here a focus on observations that were unexpected or surprising in the dataset. We then developed an assessment tool to explore how we could explain those strange results and whether we could have improved the RotaBIS data if we should have adjusted some known forces on the vaccination impact. Our hypothesis is that the Belgian program could have obtained better results from the start, despite the high observed vaccine coverage of $85 \%$, if some of the forces had been better tackled at the start. The primary focus of the simulation was to look at those forces that act during the period of vaccine initiation and whether the exceptions could subsequently have been reduced. This should provide valuable insights for countries wishing to initiate a rotavirus vaccination program.

\section{METHODS}

\section{Observational Study}

RotaBIS is a retrospective, observational hospital-based database study measuring the RV vaccination impact (RVI) relative to the prevaccination period [17]. Data from 2005 to 2019 have been split into two periods: the pre-vaccination period (2005-2006) and the vaccination period (2007-2019). The proportion of RV positive test results pooled per year for the vaccination period (2007-2019) is reported for hospitalized and ambulatory cases together, and compared with the pre-vaccination period (2005-2006) for six age groups: $0-2$ months, $>2-12$ months, $>1-2$ years, $>2-3$ years, $>3-$ 4 years, and $>4-5$ years. A specific analysis evaluated the hypothesis that the vaccine could reduce the average hospital duration of RV disease, as analyzed by source of infection (nosocomial or community-acquired) [19]. The data also helped to estimate the potential gain in hospital bed days avoided over time due to the vaccination program [20]. Statistical analyses of significant differences between groups and trends evaluated were assessed with analysis of variance (ANOVA) testing ( $F$ test, $p<0.05$ ).

Several assumptions underlie the evaluation like the catchment area that remained the same throughout the observation period, no change in rules for testing for RV disease in children during the period, and no change over the years in the criteria for hospitalizing patients with RV disease. The study received approval by the ethical committee of each participating center (see Appendix 2 in the supplementary material). The study was performed in accordance with the Helsinki Declaration of 1964, and its later amendments. Consent to participate was not required as this was a retrospective study. There is no identifying information in this manuscript.

\section{Unexpected Observations}

Given the large dataset we have with RotaBIS over a long observation period of the vaccine impact, we were particularly interested in 
looking at numbers measured at different time points on the herd effect, on the subsequent annual reduction in hospital care (the RVI score), and on age shifts in the remaining disease burden.

\section{Assessment Tool}

If unexpected observations were found, it would be useful to explain those data through an in-depth analysis of the forces acting on the vaccine impact by developing an assessment tool or model. An initial mathematical equation for calculating the RVI score accounting for the different forces was presented in a previous article on RotaBIS [16]. In the present analysis, we further expanded on those forces, including infection seasonality, vaccine coverage, vaccine effect, and five other variables (Fig. 1). Equations have been constructed with the different forces identified. Values were imputed for each force that, when combined, mimic the observed RVI data of RotaBIS over time (see Table 1 and Appendix 1 in the supplementary material for the equations and a full list of data input). Working with the assessment tool to explain the reported RotaBIS data over time with the observed exceptional results if present should be helpful for identifying the forces at the start of the vaccination program that could have an impact on the RVI score. Improving those forces could lead to better overall results of RV vaccination programs. We therefore formulated a scenario in which we challenged the values of the forces that replicate the observed RotaBIS data. We explored this by populating the equation tool with new input data (final column in Table 1) and comparing the results with the RotaBIS data to illustrate the difference.

Values for fitting the observed data from RotaBIS to the equation output were identified using a measure of goodness of fit test (root mean square error [RMSE] score) between observed and modeled data (Table 1). The adjusted age-distribution of the hospital care cases at the start of the exercise was equal to the

\section{RV-hospitalisation rate}

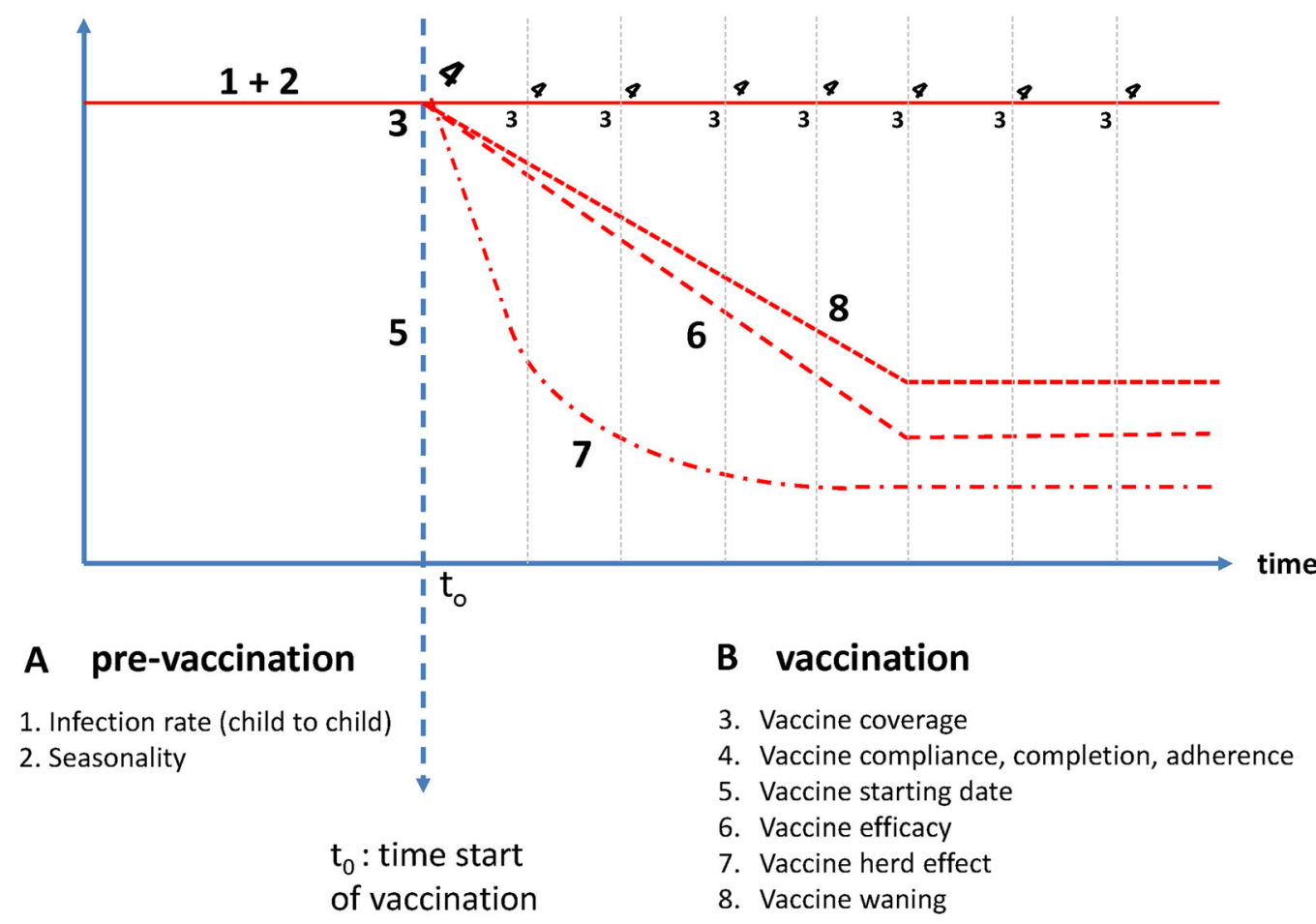

Fig. 1 Different forces identified that could influence disease spread and vaccine impact. RV rotavirus 
Table 1 Data input

\begin{tabular}{|c|c|c|c|c|c|}
\hline Model construction & Parameter & & Value & Source & $\begin{array}{l}\text { Scenario } \\
\text { analysis }\end{array}$ \\
\hline Advanced age-distribution model & \multirow{2}{*}{\multicolumn{2}{|c|}{$\begin{array}{l}\text { Disease distribution per age } \\
\text { group ( } 5 \text { age groups pre } \\
\text { vaccination) }\end{array}$}} & & Standaert et al. [16] & \\
\hline $\begin{array}{l}\text { VE (Vaccine efficacy), compliance, completion, } \\
\text { coverage, coverage at the peak, adjustment }\end{array}$ & & & & & \\
\hline \multirow[t]{10}{*}{ factor } & \multicolumn{2}{|l|}{$0-1$ years } & $50 \%$ & & \\
\hline & \multicolumn{2}{|l|}{$>1-2$ years } & $35 \%$ & & \\
\hline & \multicolumn{2}{|l|}{$>2-3$ years } & $11 \%$ & & \\
\hline & \multicolumn{2}{|l|}{$>3-4$ years } & $3 \%$ & & \\
\hline & \multicolumn{2}{|l|}{$>4-5$ years } & $1 \%$ & & \\
\hline & \multicolumn{2}{|l|}{$\mathrm{VE}$} & $95 \%$ & $\begin{array}{l}\text { Vesikari et al. } \\
\text { [28] }\end{array}$ & \\
\hline & \multicolumn{2}{|c|}{ Vaccine coverage (Cov) } & $85 \%$ & $\begin{array}{l}\text { Standaert et al. } \\
\quad[16]\end{array}$ & $90 \%$ \\
\hline & \multicolumn{2}{|c|}{$\begin{array}{l}\text { Compliance (Com) and } \\
\text { completion (Comp) }\end{array}$} & $95 \%$ & $\begin{array}{l}\text { Standaert et al. } \\
\quad[16]\end{array}$ & \\
\hline & \multicolumn{2}{|c|}{$\begin{array}{l}\% \text { of target group covered } \\
\text { (herd status) }\end{array}$} & $40 \%$ & $\begin{array}{l}\text { Standaert et al. } \\
\quad[16]\end{array}$ & $85 \%$ \\
\hline & \multicolumn{2}{|c|}{ Adjustment factor (AF) } & 2.26 & Hypothetical & 1.23 \\
\hline Waning & \multicolumn{2}{|c|}{ Per year after 1 st year } & $3 \%$ & Hypothetical & $10 \%$ \\
\hline \multirow{13}{*}{$\begin{array}{l}\text { Herd effect }(\mathrm{H}) \text {, conditional by age and vaccine } \\
\text { coverage rate of the } 1 \text { st year during the peak } \\
\text { season ( } 1 \text { st column) }\end{array}$} & Age group & $\begin{array}{l}\text { Vaccine } \\
\text { coverage rate }\end{array}$ & $\begin{array}{l}\text { Herd } \\
\text { effect }\end{array}$ & Hypothetical & \\
\hline & \multirow[t]{3}{*}{$1-2$ years } & $>85 \%$ & $70 \%$ & & $80 \%$ \\
\hline & & $>45 \%$ & $15 \%$ & & \\
\hline & & $<45 \%$ & $10 \%$ & & \\
\hline & \multirow[t]{3}{*}{$>2-3$ years } & $>85 \%$ & $65 \%$ & & $70 \%$ \\
\hline & & $>45 \%$ & $10 \%$ & & \\
\hline & & $<45 \%$ & $5 \%$ & & \\
\hline & \multirow[t]{3}{*}{$>3-4$ years } & $>85 \%$ & $60 \%$ & & $65 \%$ \\
\hline & & $>45 \%$ & $5 \%$ & & \\
\hline & & $<45 \%$ & $0 \%$ & & \\
\hline & \multirow[t]{3}{*}{$>4-5$ years } & $>85 \%$ & $55 \%$ & & $60 \%$ \\
\hline & & $>45 \%$ & $0 \%$ & & \\
\hline & & $<45 \%$ & $0 \%$ & & \\
\hline
\end{tabular}


results in the pre-vaccination situation. An adjustment factor (AF) has been introduced and was needed when multiplying the four value sets of vaccine efficacy, coverage, compliance, and completion by the percentage of the target group covered during the normal peak season. These forces are correlated and may therefore not have a full multiplicative effect [21].

To assess the improvement of the vaccination program, three critical elements must be clarified: who are the biggest transmitters of the virus within the target group of the children up to 5 years old; showing that a high vaccine coverage of the big transmitters will achieve a major vaccine impact (direct and indirect vaccine effect); identifying the fastest way to obtain a high vaccine coverage of the big transmitters taking into account the vaccine safety profile with the age restrictions.

The expectations are that the herd effect in unvaccinated age groups is likely to be maximized if the highest virus transmitters are well covered through vaccination at the start of the campaign. This high impact will also have implications for the subsequent effect of the vaccine over the midterm.

To identify the age group within the target group of children that is likely to be the major transmitter of the virus, we referred to the natural history data of the disease as a function of time and age, obtained in the RotaBIS data prior vaccination. The age-time disease density graphs will indicate the concentration and the direction of the disease spread across the different age groups with time, with the assumption that the age group with the highest density is likely to spread the disease most. If the major virus transmitter group is vaccinated with a very high coverage rate at an early stage during the usual peak season, an important herd effect should be visible in the year after the start of the vaccination program. The time of initiating the vaccination is therefore a function of the accumulated vaccine coverage rate of the birth cohort prior to the first subsequent disease peak period. The shorter that time is, the lower the vaccine coverage will be, leading to a smaller herd effect.

\section{RESULTS}

\section{Observational Study}

The vaccine coverage during the RotaBIS study period has remained the same in Belgium, at around $85 \%$. The distribution between the two vaccines, the single human RV strain and the human-bovine reassortant, was around $85 \%$ for the single human RV strain vaccine across the years [22].

Data on the reduction of positive RV test results on hospital care (RVI) are compared with the pre-vaccination period over a period of 13 years (Table 2 and Fig. 2). A gradual decrease is observed in RV-related hospital care relative to the pre-vaccination period (green boxes, Fig. 2), reflecting decreasing RVI scores up to 8 years post vaccine introduction, followed by a period of small peaks appearing in year 9 and 11 , ending by a further decline. The blue boxes in Fig. 2 show the direct impact of the vaccine, and the light red boxes show the indirect effect. The indirect or herd effect represents 14\% of the impact in the first year, but decreases to $7 \%$ in the second year, and even lower (4-5\%) thereafter. A small herd effect remains over time that is explained by the indirect impact of the vaccine maintained in the $0-2$ months old age group [from 114 cases pre vaccination to 27 cases in 2019 (see Table 2)].

Table 2 also reveals the split by age group per year and shows some age shifts occurring over time. Whereas the RV circulation predominates in 3-24 months old with $81 \%$ of the cases $(1091 / 1345)$ in the pre-vaccination period, when vaccination is well established after 10 years, the main spread is still among the same age group $(73 \% ; 160 / 217)$ but with a greater spread to the younger ones ( $0-2$ months old) from $8 \%$ pre-vaccination to $14 \%$ on average. The small peaks in years 9 and 11 post vaccination are concentrated in the group aged 3-12 months old.

Table 3 and Fig. 3 show the age distribution per year of RV nosocomial infections and the absolute number with its relative importance to the total number of RV hospitalization events per year. An absolute decrease is observed over 


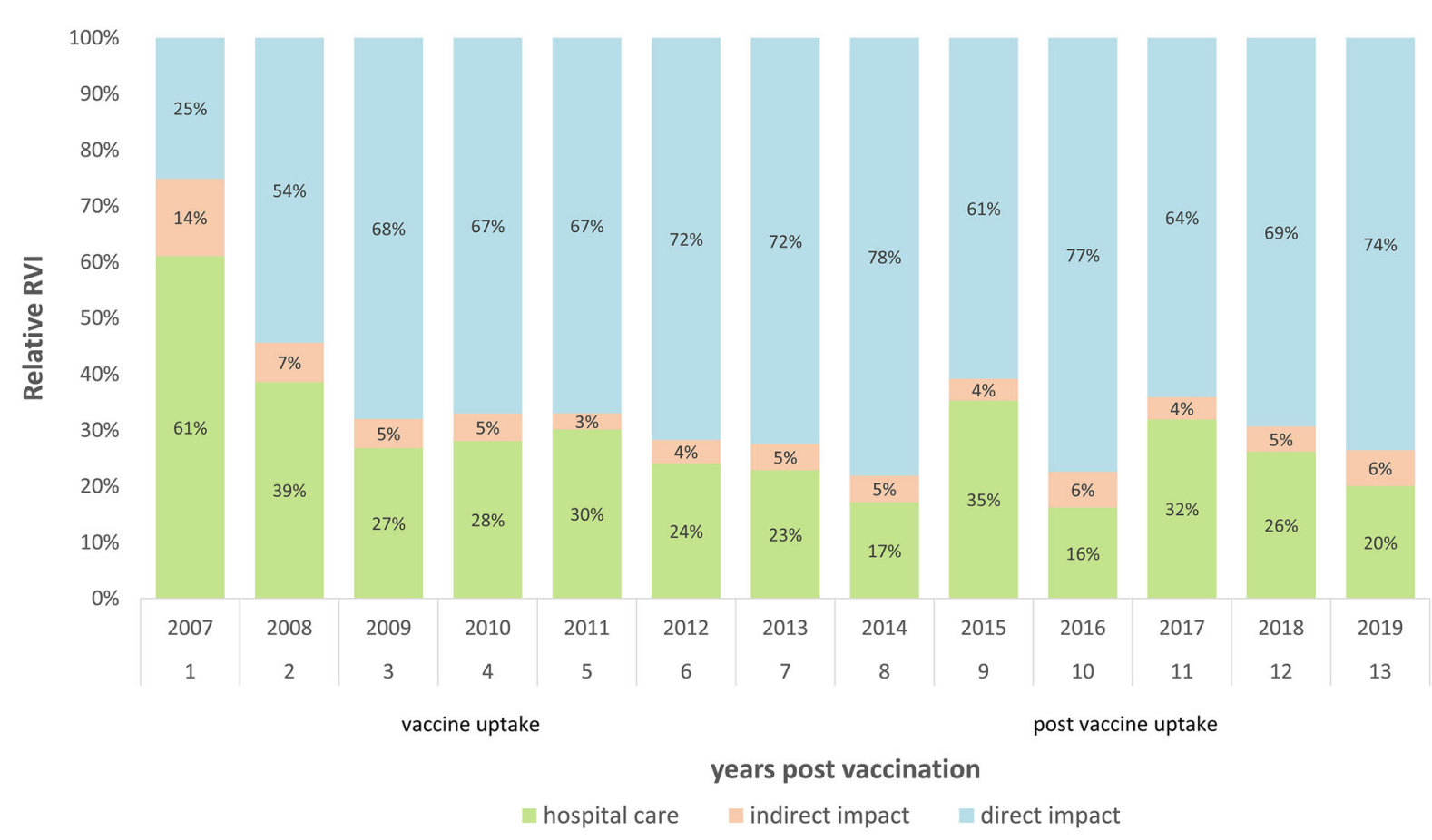

Fig. 2 Relative RVI for hospitalization (green), relative to the pre-vaccination period, with direct (blue) and indirect impact (red). RV rotavirus, RVI RV vaccination impact

time after the start of vaccination, reaching $10 \%$ [17 (year 2019)/176 (pre-vaccination)] of absolute cases, when comparing the pre-vaccination period with the latest vaccination year (Table 3 ) and half the proportion $(6 \% / 13 \%)$ of the prevaccination period [ANOVA testing: $F$ test, 30.7 $(p<0.001)$ ] (Fig. 3), with a decreasing proportional trend. The age distribution for nosocomial infections also has a shifting pattern as observed for the overall events, with the relative importance of the youngest age group (02 months) that is apparent over time, increasing from $25 \%$ (44/176) pre-vaccination to $41 \%$ (7/ 17) in 2019 (see Table 3).

Finally, the duration of hospitalization for community-acquired events slightly decreased by approximately 1 day on average, from 4.9 days pre-vaccination $(95 \%$ confidence interval [95\% CI] $4.7-5.1$ ) to 3.9 days (95\% CI 3.7-4.1) in the year 2019 (ANOVA testing, $F=8.196(p<0.001))$. The same type of result was not seen for nosocomial infection, where the average hospital duration pre-vaccination was 16 days [95\% CI 13.3-18.6; $n=176$ (years 2005 and 2006)], and after 13 years of vaccination the average duration was 19 days (95\% CI $8.4-29.8 ; n=17)$. The absence of an observed decreasing trend may be explained by the low number of events in 2019 as compared with the pre-vaccination period. Small numbers with one outlier can heavily skew the mean.

With the current data of RotaBIS, one can estimate how many RV-related hospital bed days have been avoided since the introduction of the vaccine. Hospitalization bed occupancy for 1 year in the pre-vaccination period was estimated at 7685 bed days. Over 13 years, this would add up to 99,907 bed days occupied for $\mathrm{RV}$ disease, if vaccination had not been introduced. The observed bed days accumulated over 13 years was 27,477 bed days, or a $72.5 \%$ reduction rate. When comparing the last year (2019) with the pre-vaccination year, the improvement reaches an 87\% reduction (1002/ 7685).

\section{Unexpected Observations}

We observed a small direct vaccine effect (25\%) at the start of the vaccination campaign in 2007 

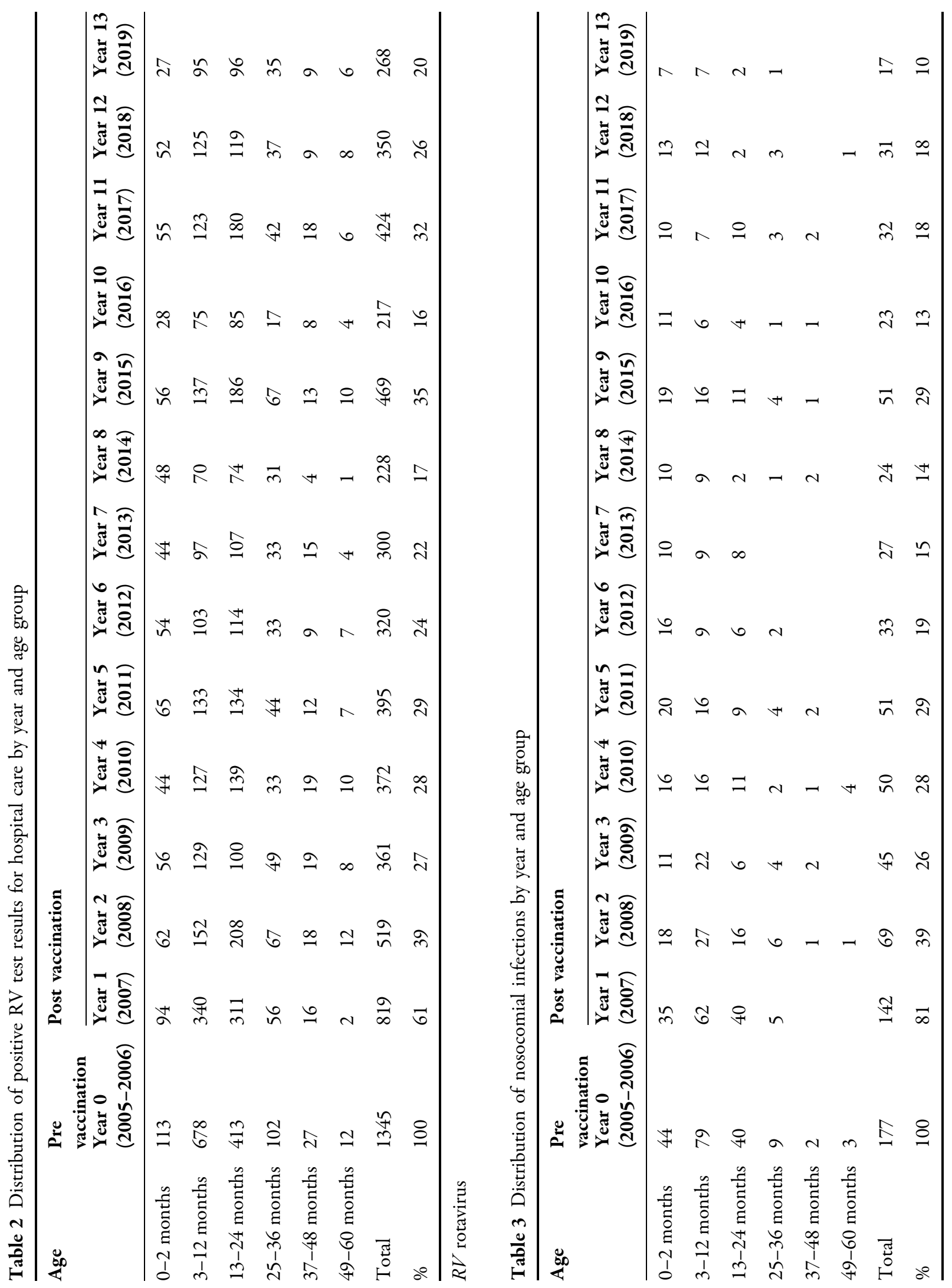


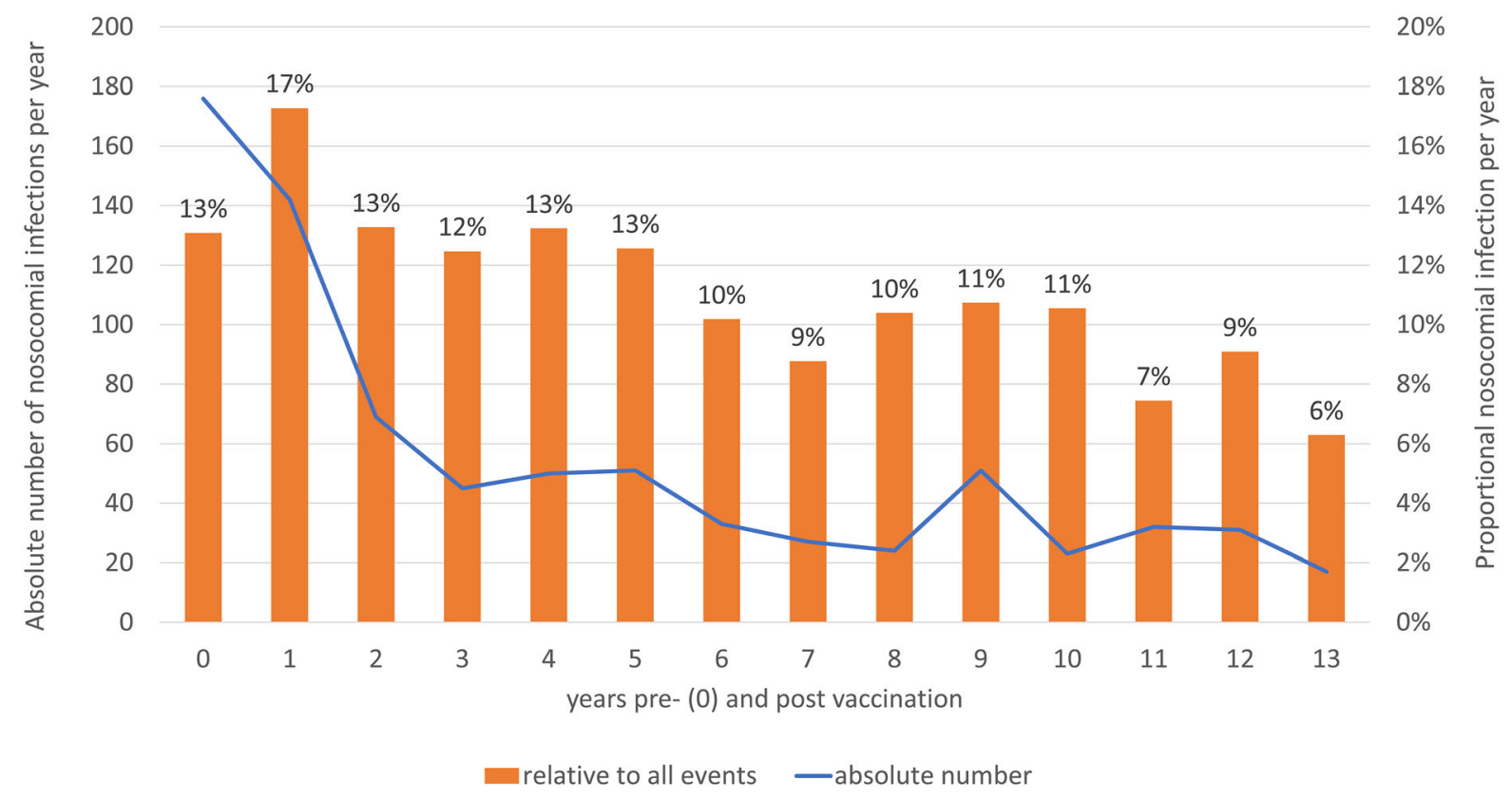

Fig. 3 Absolute number of nosocomial infection per year and its relative importance as compared with the total RV hospital events in the post-vaccination period. RV rotavirus

and, related to that, a small indirect or herd effect $(14 \%)$. The reason we are claiming that the indirect effect is small is because the unvaccinated potential age group pre-vaccination on which the herd effect could have an impact represents $50 \%$ of the at-risk group [see Table 2 , first column (667/1345)] and only 14\% is cached. The next surprising results are the flattening of the decreasing RVI curve after 3 years. We would normally have expected a further substantial additional decrease over time, but that is not happening. Finally, as already mentioned, we observed small increases in events in years 9 and 11 post vaccine introduction.

\section{Assessment Tool}

The responses to the three critical questions we identified that better clarify the vaccine impact data are that pre-vaccination data of RotaBIS reveal that the disease frequency as a function of age (see Table 2, first column) follows a Weibull distribution (alpha 1.6769; beta 15.781; shift -2.4601$)$, with more hospitalization at younger ages. Fifty percent of the hospitalization events occur during the age range of 3-14 months. If this age group is the major transmitter of the virus during the peak season, the highest density of hospitalization in the other age groups should also appear during the same period, if the virus circulation is easy and dense. Figure 4 shows that this pattern was observed during the pre-vaccination period, with a high concentration of hospitalizations around the same period of the year for all the different age groups. The black box in Fig. 4a indicates the age group in their first year and the period in weeks with the highest concentration of hospital events.

The age-time disease density graph one year later, after introducing the vaccine (Fig. 4b), indicates an important change in density spread. The highest concentration has shifted to the right by 1 month, and the decrease appears among the unvaccinated groups as well as among those vaccinated (the age group 3-5 months old). The data therefore support the hypothesis that a high coverage of those younger than 12 months old during the peak season in the first vaccination year should result in an important herd effect 1 year later. 

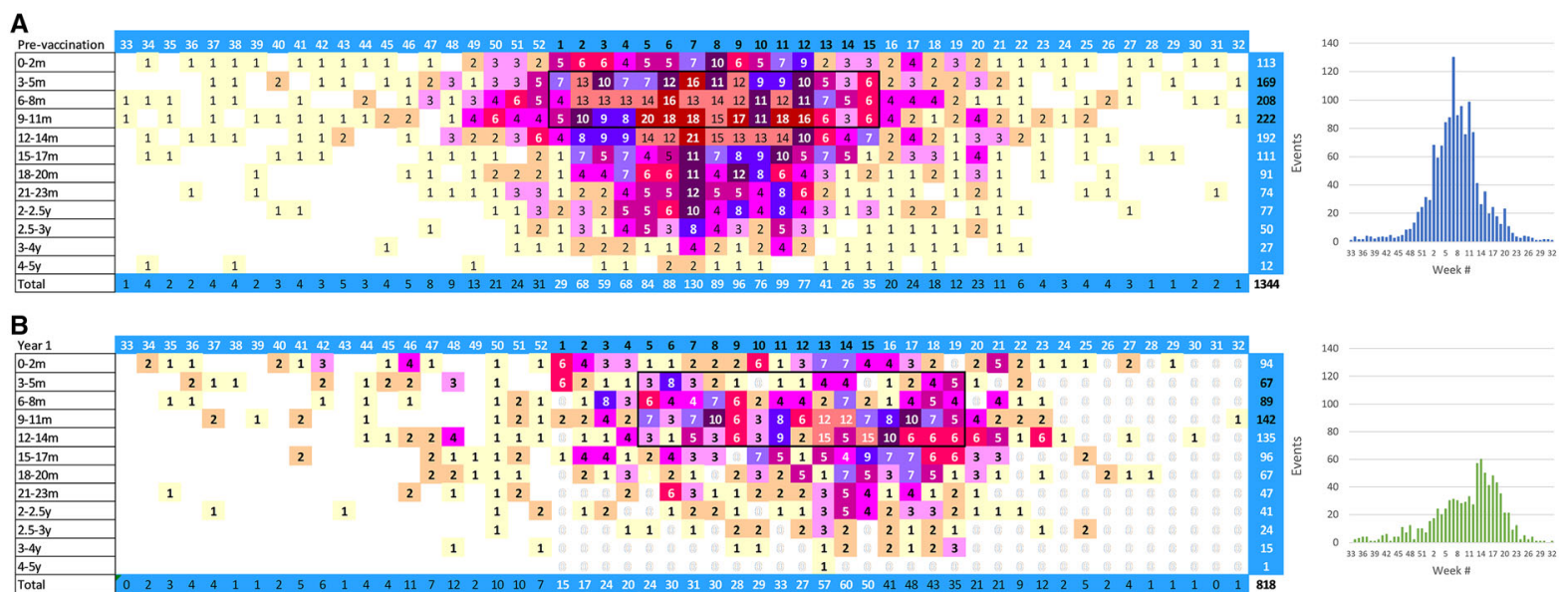

Fig. 4 Time-density graph of hospitalizations per week for 13 age groups, pre-vaccination (a) and first year postvaccination (b). $\mathrm{m}$ months, y years. Note: Discrepancies

To obtain a maximum vaccine coverage rate of these high transmitters in the first year, the vaccination starting date must be at the right time. Assuming an equal birth rate each month over one year and a vaccine coverage rate of $90 \%$ of newborns, if vaccination is started in July, the proportion of immunized children during the next peak season will be around $70 \%$. If vaccination starts later, in November, with the same birth rate assumption per month but a lower vaccine coverage (85\%) as was the case in Belgium, the vaccine coverage rate would be much lower (around 35\%) during the peak season. Therefore, the direct and the herd effect would be less pronounced if a country starts vaccination late in the calendar year, as was observed in Belgium (Fig. 2).

Finally, Fig. 5 illustrates the scenario analysis done with the assessment tool that includes an early start of vaccination (see Table 1, last column for data input in the model). Combining an overall high vaccine coverage rate $(90 \%)$, with a high compliance and completion rate $(95 \%)$, a coverage rate of the high transmitters during the first peak season of $85 \%$, and an AF of 1.23, the model indicates that an RVI score of $90 \%$ would be reached after 5 years, and potentially reaching $98 \%$ in year 13 . One feature seen in this scenario is the high level of herd effect achieved during the first year after the vaccine introduction. It has been estimated between cells and the line or column total are due to rounding in the cells

at around 58\%-relative importance in the vaccine effect during the first year (45\%/ $(45 \%+33 \%)$ )-instead of the current measurement of $36 \%(14 \% /(14 \%+25 \%))$ (Fig. 2$)$. Another feature of the combined effect of high direct vaccine impact resulting from the high vaccine coverage of the main transmitters and the important herd effect is the limited manifestation of the small peaks observed several years after the vaccine introduction. The RVrelated hospital bed days avoided could now reach $89 \%$ in this scenario.

\section{DISCUSSION}

The RotaBIS study, with observations of RV-related hospital care over 15 years in Belgium now, has interesting features to scrutinize. The decrease in RV-specific hospitalizations in children less than 5 years old is maintained over time, although it demonstrated some small biennial peaks 9 and 11 years post vaccine introduction. An explanation for those peaks is difficult to provide given the current vaccine impact, but we hypothesize that other sources of infection could play a role [23]. Also interesting to note is the continuous reduction in nosocomial infections to very low levels. We observe a shift of the disease to younger ages, which could be an incentive for Belgium to try 


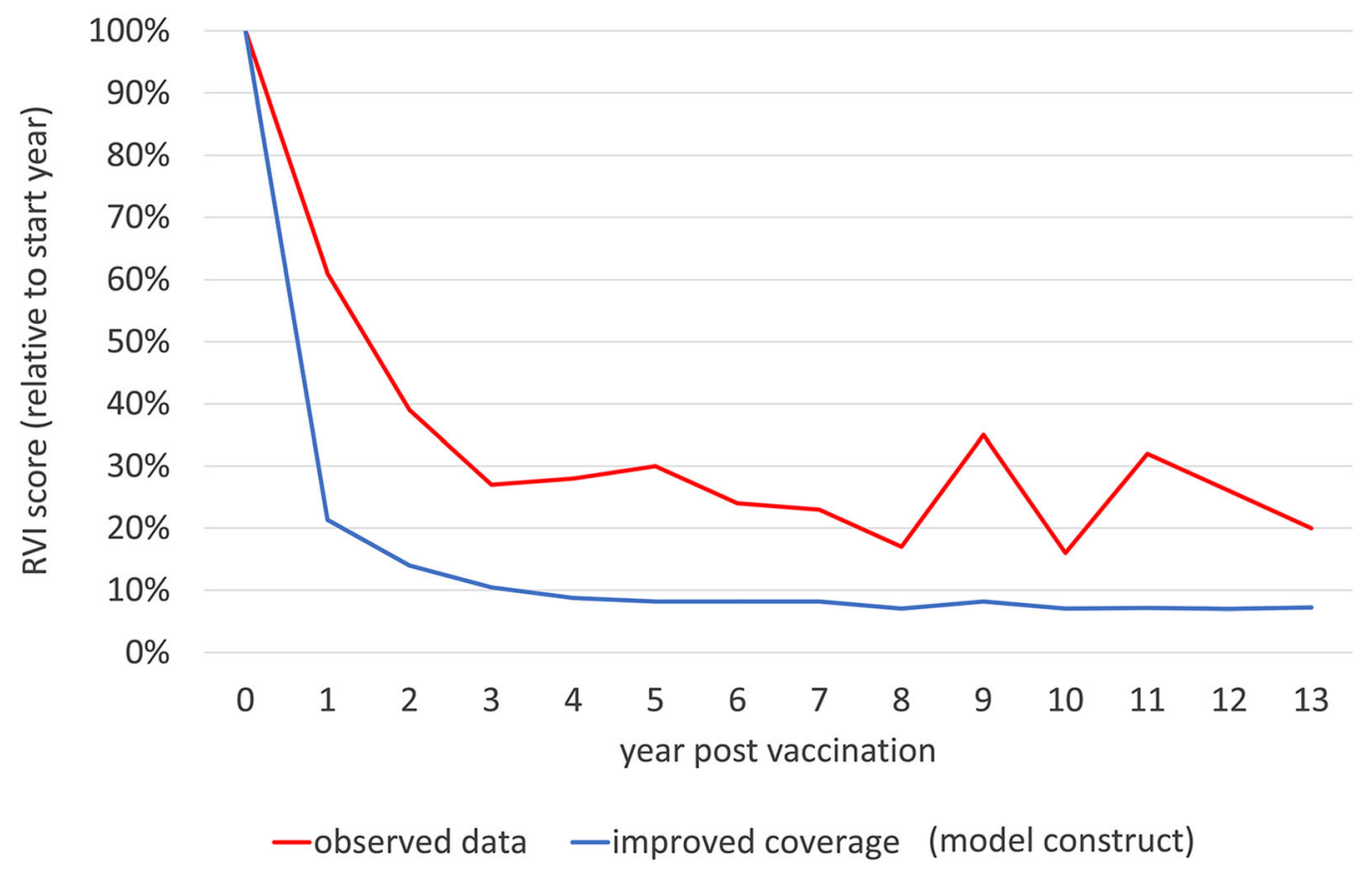

Fig. 5 Scenario analysis of early starting date for vaccination (blue line) versus late starting date close to the peak season (red line). Note: model construct (blue line), observed data (red line). RV rotavirus, RVI RV vaccination impact

to initiate vaccination at an earlier age. Finally, the high number of bed days avoided during each winter period since the introduction of the vaccine may certainly enhance the quality of care in the hospital environment as already reported [20].

The exercise with the simulation model indicated that better results could be obtained if selecting a better starting date for introducing the mass vaccination campaign and getting a very high vaccine coverage rate of the high transmitters of the virus (children aged 312 months old). This information is important to share with countries who have not yet started with their RV vaccination campaign. Belgium may be considered successful with the RV vaccination having a high vaccine coverage rate of around $85 \%$, but that may not be sufficient to obtain optimal results. The herd effect measured during the first 2 years was marginal (see Fig. 2); that effect could have been much more pronounced when operating under better conditions, namely a good starting date and coverage rate as seen in the vaccine initiation program of England and Wales [7]. This process is the cause of the big herd effect in the first years after the vaccine introduction. That effect will, however, never reach a 100\% impact on the other age groups because they are still exposed to the wild-type virus coming from other sources such as older children and caregivers [16]. There is a continuous contact pattern between the age groups of young children with the transmission of the virus from groups outside the 5-year-olds [23]. The effect of these other sources of infection possibly contributed to the suboptimal vaccine impact observed in Belgium following the vaccine introduction after 3 years (flattening the curve).

The optimal aim of the vaccine introduction is to create a maximum reduction of the virus spread during the first 2 years of vaccine implementation to obtain the best long-term impact. The virus is very contagious, and the transmission therefore needs to be blocked as much as possible as early as possible. Under such circumstances, sources of infection are less strong, and susceptible individuals are less prevalent during the midterm post vaccine period. Disease peaks may therefore appear less frequently and less prominently. Therefore, it could also be that after 13 years of vaccination a 
new disease equilibrium stage may have been reached, with a further gradual improvement in the RVI score leading to the disappearance of the small disease peaks because the force of infection has become too low (the reproduction number will fall below 1 ).

Those other sources of infection need to be considered because no process of disease elimination was observed when heavily vaccinating the target group from the start [24]. In the prevaccination period, the influence of other infection sources may be marginal, as infections are dominated by the primary source, the children in the target age group. The other groups may gain in relative importance as a higher proportion of the at-risk group becomes covered by the vaccine $[23,25]$.

The biennial small disease peaks may only appear after 5 years of vaccination when full vaccine coverage has not been obtained. The pattern may change to annual peaks if the vaccine coverage and effect are low $(\leq 60 \%)$. The biennial peaks will only appear with moderate vaccine effect ( 60 to $<80 \%$ ) and coverage (75-85\%), when the wild-type virus circulation in other age groups can reach the remaining susceptible subjects in the target group at a certain threshold. Under such circumstances a recommendation to still improve the current results would be to increase the vaccine coverage rate. However, that alone may be too late to have a major influence, as the opportunity to cause a big herd effect has disappeared. Other options are to try to identify and vaccinate the other sources of infection if possible, but to reach those other sources could be difficult and an important additional cost to consider [26].

A limitation of the study was that we were unable to better explore the role that different sources of infection (older age groups and caregivers) could play in the current constellation of the study. We formulated some hypotheses, but they are difficult to test in such a study design [23]. The evaluation and interpretation of the results of the scenario analysis may be restricted to country-specific conditions with open access to hospital care. However, the disease distribution among the different age groups, especially concentrated during the first 2 years of life, indicates the importance of the vaccine impact at the start of the vaccination campaign. The same tendency in the results is expected to be seen across countries. The results only capture hospital care and do not explore the impact on primary healthcare. It is likely that there will be an effect at other levels of the healthcare organization, but much depends on how the healthcare system is organized [27]. Finally, it remains necessary to continue monitoring the vaccine effect over time, to be able to follow the effect over time. The comparison of different uptake scenarios of the vaccine in different settings/countries would be most helpful to evaluate and confirm the findings with modeled results presented here.

\section{CONCLUSION}

Careful selection of the start date for the introduction of a vaccination program against RV disease is warranted to achieve maximum health gain over time. The vaccination program should be well planned, and the objective should be clearly defined at the start. Without this focus, the goal of optimal reduction of infection may be only partially achieved. This may result in higher costs to recover the maximum impact, which could have been avoided if optimal conditions had been searched for at the start.

\section{ACKNOWLEDGEMENTS}

Rotarix is a trademark licensed to or owned by the GSK group of companies. RotaTeq is a trademark licensed to or owned by Merck.

Funding. GlaxoSmithKline Biologicals SA funded this study (NCT01563146 and NCT01563159) and the journal's Rapid Service Fees.

Medical Writing and/or Editorial Assistance. Authors would like to thank Business \& Decision Life Sciences platform for editorial assistance and manuscript coordination, on behalf of GSK. Amandine Radziejwoski coordinated manuscript development and editorial 
support. Carole Nadin (Fleetwith Ltd, on behalf of GSK) provided medical writing support.

Authorship. All named authors meet the International Committee of Medical Journal Editors (ICMJE) criteria for authorship for this article, take responsibility for the integrity of the work as a whole, and have given their approval for this version to be published.

Authorship Contributions. All authors participated in the design or implementation or analysis, and interpretation of the study; and the development of this manuscript. All authors had full access to the data.

Disclosures. Bernd Benninghoff, Priya Pereira and Badouin Standaert are employees and shareholders of the GSK group of companies. Marc Raes and Danielle Strens report fees paid to their institutions by the GSK group of companies. Marc Raes reports fees paid to him by the GSK group of companies for board memberships, lectures, travel, accommodation and meetings expenses. The authors declare no financial conflicts of interests.

Compliance with Ethics Guidelines. The study has received approval by the ethical committee of each participating center (see Appendix 2). The study was performed in accordance with the Helsinki Declaration of 1964, and its later amendments. Consent to participate was not required as this was a retrospective study. There is no identifying information in this manuscript.

Data Availability. The datasets generated during and/or analyzed during the current study are available from the corresponding author on reasonable request.

Open Access. This article is licensed under a Creative Commons Attribution-Non-Commercial 4.0 International License, which permits any non-commercial use, sharing, adaptation, distribution and reproduction in any medium or format, as long as you give appropriate credit to the original author(s) and the source, provide a link to the Creative Commons licence, and indicate if changes were made. The images or other third party material in this article are included in the article'sCreative Commons licence, unless indicated otherwise in a credit line to the material. If material is not included in the article's Creative Commons licence and your intended use is not permitted by statutory regulation or exceeds the permitted use, you will need to obtain permission directly from the copyright holder. To view a copy of this licence, visit http://creativecommons.org/licenses/by$\mathrm{nc} / 4.0 /$.

\section{REFERENCES}

1. Pindyck T, Tate JE, Parashar UD. A decade of experience with rotavirus vaccination in the United States-vaccine uptake, effectiveness, and impact. Expert Rev Vaccines. 2018;17(7):593-606.

2. Paulke-Korinek M, Kollaritsch H, Aberle SW, et al. Sustained low hospitalization rates after four years of rotavirus mass vaccination in Austria. Vaccine. 2013;31(24):2686-91.

3. Poelaert D, Pereira P, Gardner R, Standaert B, Benninghoff $B$. A review of recommendations for rotavirus vaccination in Europe: arguments for change. Vaccine. 2018;36(17):2243-53.

4. Pendleton A, Galic M, Clarke C, et al. Impact of rotavirus vaccination in Australian children below 5 years of age: a database study. Hum Vaccin Immunother. 2013;9(8):1617-25.

5. Leino T, Baum U, Scott P, Ollgren J, Salo H. Impact of five years of rotavirus vaccination in Finlandand the associated cost savings in secondary healthcare. Vaccine. 2017;35(42):5611-7.

6. Coyle D, Coyle K, Bettinger JA, et al. Cost effectiveness of infant vaccination for rotavirus in Canada. Can J Infect Dis Med Microbiol. 2012;23(2):71-7.

7. Atchison CJ, Stowe J, Andrews N, et al. Rapid declines in age group-specific rotavirus infection and acute gastroenteritis among vaccinated and unvaccinated individuals within 1 year of rotavirus vaccine introduction in England and Wales. J Infect Dis. 2016;213(2):243-9.

8. Uhlig U, Kostev K, Schuster V, Koletzko S, Uhlig $\mathrm{HH}$. Impact of rotavirus vaccination in Germany: rotavirus surveillance, hospitalization, side effects 
and comparison of vaccines. Pediatr Infect Dis J. 2014;33(11):e299-304.

9. Valcarcel Salamanca B, Hagerup-Jenssen ME, Flem E. Uptake and timeliness of rotavirus vaccination in Norway: the first year post-introduction. Vaccine. 2016;34(39):4684-9.

10. Oldin C, Golsater M, Schollin Ask L, Fredriksson S, Stenmarker M. Introduction of rotavirus vaccination in a Swedish region: assessing parental decision-making, obtained vaccination coverage and resulting hospital admissions. Acta Paediatr. 2019;108(7):1329-37.

11. Hartwig S, Uhari M, Renko M, Bertet P, Hemming M, Vesikari T. Hospital bed occupancy for rotavirus and all cause acute gastroenteritis in two Finnish hospitals before and after the implementation of the national rotavirus vaccination program with RotaTeq ${ }^{\circledR}$. BMC Health Serv Res. 2014;14:632.

12. Payne DC, Selvarangan R, Azimi PH, et al. Longterm consistency in rotavirus vaccine protection: RV5 and RV1 vaccine effectiveness in US children, 2012-2013. Clin Infect Dis. 2015;61(12):1792-9.

13. Vesikari $\mathrm{T}$, Uhari $\mathrm{M}$, Renko $\mathrm{M}$, et al. Impact and effectiveness of RotaTeq ${ }^{\circledR}$ vaccine based on 3 years of surveillance following introduction of a rotavirus immunization program in Finland. Pediatr Infect Dis J. 2013;32(12):1365-73.

14. Zlamy M, Kofler S, Orth D, et al. The impact of rotavirus mass vaccination on hospitalization rates, nosocomial rotavirus gastroenteritis and secondary blood stream infections. BMC Infect Dis. 2013;13: 112.

15. Baker JM, Dahl RM, Cubilo J, Parashar UD, Lopman BA. Effects of the rotavirus vaccine program across age groups in the United States: analysis of national claims data, 2001-2016. BMC Infect Dis. 2019;19(1):186.

16. Standaert B, Strens D, Alwan A, Raes M. Medium- to long-term impact of rotavirus vaccination on hospital care in Belgium: a 7-year follow-up of the Rotavirus Belgium Impact Study (RotaBIS). Infect Dis Therapy. 2016;5(1):31-44.

17. Raes M, Strens D, Vergison A, Verghote M, Standaert B. Reduction in pediatric rotavirus-related hospitalizations after universal rotavirus vaccination in Belgium. Pediatr Infect Dis J. 2011;30(7): e120-e125125.
18. Standaert B, Gomez JA, Raes M, Debrus S, Velázquez FR, Postma MJ. Impact of rotavirus vaccination on hospitalisations in Belgium: comparing model predictions with observed data. PLoS ONE. 2013;8(1): e53864.

19. Standaert B, Strens D, Li X, Schecroun N, Raes M. The sustained rotavirus vaccination impact on nosocomial infection, duration of hospital stay, and age: the RotaBIS study (2005-2012). Infect Dis Ther. 2016;5(4):509-24.

20. Standaert B, Alwan A, Strens D, Raes M, Postma MJ. Improvement in hospital Quality of Care (QoC) after the introduction of rotavirus vaccination: an evaluation study in Belgium. Hum Vaccines Immunother. 2015;11(9):2266-73.

21. Kurosky SK, Davis KL, Krishnarajah G. Effect of combination vaccines on completion and compliance of childhood vaccinations in the United States. Hum Vaccines Immunother. 2017;13(11): 2494-502.

22. Braeckman $\mathrm{T}$, Theeten $\mathrm{H}$, Lernout $\mathrm{T}$, et al. Rotavirus vaccination coverage and adherence to recommended age among infants in Flanders (Belgium) in 2012. Euro Surveill. 2014;19(20):20806.

23. Markkula J, Hemming-Harlo M, Savolainen-Kopra C, Al-Hello H, Vesikari T. Continuing rotavirus circulation in children and adults despite high coverage rotavirus vaccination in Finland. J Infect. 2020;80(1):76-83.

24. Glass RI, Parashar U, Patel M, Gentsch J, Jiang B. Rotavirus vaccines: successes and challenges. J Infect. 2014;68(Suppl 1):S9-18.

25. Crawford SE, Ramani S, Tate JE, et al. Rotavirus infection. Nat Rev Dis Primers. 2017;3:17083.

26. Wolff E, Aronsson B, Hultstrand M, Brouwers L. Cost-effectiveness analyses of different vaccination strategies to reduce pertussis among infants in Sweden. J Infect Dis Epidemiol. 2019;5(1):065.

27. Standaert B, Harlin O, Desselberger U. The financial burden of rotavirus disease in four countries of the European Union. Pediatr Infect Dis J. 2008;27: S20-S2727.

28. Vesikari T, Karvonen A, Prymula R, et al. Efficacy of human rotavirus vaccine against rotavirus gastroenteritis during the first 2 years of life in European infants: randomised, double-blind controlled study. Lancet. 2007;370(9601):1757-63. 